\title{
The Publishing Patterns Of Mid-Career Economics Doctoral Graduates
}

\author{
Jeff Heinrich, (Email: heinricj@uww.edu), University of Wisconsin, Whitewater
}

Russ Kashian, (Email: kashianr@uww.edu), University of Wisconsin,Whitewater

\begin{abstract}
We present publication data for seasoned graduates of 120 economics Ph.D. programs. The data show that while publishing output is highly concentrated among the graduates of top programs, the inclusion of a wider pool of academic journals provides an opportunity to visualize the publishing potential of second and third tier programs. This paper's distinctive methodology concurs with the rich history of literature that determines the top tier of academic programs. However, expanding the list to the full EconLit database allows a glimpse at the publishing trends of the lesser ranked programs. This provides an opportunity for small regional and liberal arts colleges and universities to evaluate graduate programs according to their distinct needs. In addition, inclusion of field designations (such as international, labor, monetary, etc) as grouped by the American Economic Association classification allows insight into the potential for specialization among programs.
\end{abstract}

\section{INTRODUCTION}

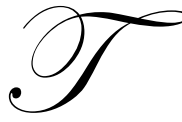

he question of publishing productivity within the economics profession is a well-established line of inquiry. It is typical for such efforts to assess productivity on the basis of the affiliated program, either as the program's faculty or graduates. In this paper we utilize many of the important ranking qualities used in the previous literature to rank programs according to graduate output, but with a more expansive pool of journals and a breakdown of program rankings by the field of the graduate.

As noted by the preponderance of the literature, it is common practice for $\mathrm{PhD}$ programs to promote their departments as a function of inputs provided into graduate education. In effect, a program is the product of professors' qualifications: their publishing history and their degrees. Research facilities, monetary opportunities, and other factors augment this product. This is an excellent standard: students strive to study with the best minds in the field in quality facilities. A number of papers have examined the faculty output dimension, ranking programs according to faculty publishing. Moore (1972) examines faculty publication patterns in 45 economics departments. Moore further limits the pool to seven "elite" schools possessing a distinct reputation advantage. Neimi (1975) uses 24 journals, but limited this faculty based ranking to 100 schools. Graves et al (1982) and Hirsch et al. (1984) use 24 journals and 240 departments. Scott and Mitias (1995) rank programs based on the number of pages published in the top 36 (and the top 5) journals, output per faculty member, and a differentiation between stock and flow rankings. Hodgson and Rothman (1999) limit their faculty publication rankings to journals created before 1995. This style of literature continues (Tschirhart, 1989; Trembay et al, 1990; and Kalaitzidakis, Mamuneas, \& Stengos, 2001).

However, in the tradition of Laband (1986), an alternative standard of ranking programs embraces the publishing patterns of their $\mathrm{PhD}$. Graduates, an output measure perhaps of more interest to prospective students and faculty recruitment committees. Based on this standard, one can rank programs according to the publishing activity of alumni. Since, for many institutions, refereed publications serve as the "coin of the realm", prospective students may aspire to schools that produce publishing graduates. Laband (1986a) ranks the top economics departments by the research productivity of their graduates, but considers only publications in the top 24 economics journals as selected by Graves et al (1982). Collins, Cox and Stango (2000) consider the publishing of recent graduates in a larger pool of 36 top economics journals, but only the graduates of 50 highly regarded economics doctoral programs. In one application, Hutchinson and Zivney (1995) used 20 years of data on a sample of PhD graduates to create a graduate 
profile, finding that $39 \%$ of the sample produced at least one article and $10 \%$ did not publish until 6 years after the doctorate. However, their paper did not track the graduating institution. Instead, it concentrates on the publication patterns of a sample of PhD graduates over a twenty-year span. Collins, Cox and Stango (2000) approach the question of publishing patterns by examining the students according to school. This paper selects the publishing patterns of recent graduates of 50 highly regarded economics doctoral programs. The publishing patterns are further limited to the top 36 economic journals. This paper resembles Laband (1986), who ranks the top economics departments by the research productivity of their graduates. However, Laband's sample is limited to twenty-four journals.

This paper expands on these efforts in several important ways. First, it considers a larger pool of both graduates, programs, and journals to evaluate. Prior literature concentrated on the "premier" institutions and programs, whereas we offer a more comprehensive look. Second, we are able to break down the publishing record of $\mathrm{PhD}$ recipients not just by these measures, but also by the field in which they received their doctorate. The sample we employ consists of graduates of United States PhD granting institutions from 1991 to 1994. The basis of this data is the lists of $\mathrm{PhD}$ recipients reported by graduate programs to the AEA and published in the Journal of Economic Literature's $4^{\text {th }}$ issue for those years. Gaps in the reporting by programs undoubtedly result in omissions, but such is the nature of self-reported data and this ranking nonetheless includes all U.S. universities listed in the JEL. The publication record of these economists is taken from the EconLit database, including all entries therein up through December 2003, permitting ample time for their publishing potential to be realized.

This paper's approach of tracking all the publications of the graduates of all universities, disaggregated by field, has several advantages. First, while it is quickly apparent that historically highly ranked programs continue to be highly ranked, there is information to be gleaned from analyzing the second and third tier programs. In addition, by looking at the self-reported field categories of dissertations, it is informative to look to the propensity to publish from fields within an institution as an indication of specialty. Indeed, a program below the first tier in the aggregate may very well show as an outstanding producer of publishing graduates in a particular field.

Like the prior literature this paper investigates publishing in previously-determined "quality" journals, but we also augment this by including all publications in the EconLit database. While journal "quality" is especially relevant to those premier programs that expect their junior faculty will publish in the leading journals, many universities simply seek candidates who publish in peer-reviewed journals, or on occasion even any journal. The expectation that these candidates will publish in one of the described "quality" publications is unwarranted. Tenure determination is often based on a binary determination of publishing or not, while quality is a contributor to merit raises and reviews. As a result, omission of the smaller journals provides an elite view of the profession that is not held by all candidates or colleges.

As programs attempt to differentiate their undergraduate programs, pressure to publish, particularly for assistant and associate professors, is heightened. In addition, pressure to bring in faculty who are both capable and motivated to publish is increasing. Finally, doctoral programs continually seek to promote their program in terms of the success of their graduates. The mapping of the terrain of $\mathrm{PhD}$ institutions in regards to the publishing patterns of a group of graduates thus serves two legitimate purposes. The first regards the choice of potential schools by the PhD applicant/candidate. For the student, this selection may be relevant for determining both the path to academic economics and/or private sector careers. While the ultimate determination is much more complex, guidance is warranted regarding the historic performance of graduates in the publishing arena, either by school or by field. The rankings arrived at in this paper can assist $\mathrm{PhD}$ students in their selection of programs to suit their professional goals.

The second rationale for the mapping is to provide guidance to both faculty and administrators of past performance. It offers insight on the trends in the profession, as related to in-house standards for promotion and tenure. Given those standards, recruitment committees can use these rankings to assist in their assessment of candidates for their publishing potential based on the degree-granting institution as well as the primary and perhaps secondary fields of the applicants. In addition, this paper makes an effort to identify those graduates who published papers in journals considered outstanding in their field. Faculty position announcements often specify interest in a particular field, so disaggregation by field would seem a useful expansion of the literature for such searches. To work 
toward these purposes, this paper (1) reviews the productivity of a cohort of graduates, (2) assesses the quality and quantity of their publishing record, and (3) evaluates publishing patterns by research fields.

\section{DATA AND METHODOLOGY}

Each December, the Journal of Economic Literature publishes the list of Ph.D. graduates as provided by the academic institution. This list includes student name, school name and dissertation field by JEL code. In this paper we track graduates receiving their degree within the period of 1991-1994. Previous research (Laband, 1986a; Hutchinson and Zivney, 1995) noted that the JEL database contains various faults including entries from associated fields, such as agricultural economics, consumer economics, and other areas related to economics (Gilley 1986). Laband (1986b) responds that these criticisms are valid but not lethal.

Our productivity measure, publications per graduate, includes all EconLit indexed articles. This encompasses a total of 1014 different publications. Schools are ranked according to the publishing productivity of their graduates in these journals. Prior literature restricts the analysis to a few, top tier journals. This paper continues in that effort, also ranking programs by the publishing productivity of their graduates in just the 36 top journals as identified by Scott and Mitias (1996). Lastly, to gauge productivity within the putative field of the graduate, we rank programs by average graduate productivity in the top field journals, as identified by Axarloglou and Theoharakis (2003) (Appendix 1), in the graduate's field. We perform this ranking by school in each journal category for the aggregated graduate pool. Segregating graduates by dissertation field as reported in the JEL recalculates this rank. We rank only the top 15 positions in each instance, but allow for ties to result in more schools being so ranked (for example, two programs tied for $15^{\text {th }}$ place or 3 tied for $14^{\text {th }}$, etc.).

This analysis is not without it's caveats. First, some of the fields are small in terms of graduates. As a result, a program may only have one or two graduates in that field. In that case, the ranking of the program in that field depends entirely upon the productivity of that one or two graduates. The question then is whether that reflects a very small selective program turning out highly productive graduates, or is more a "one-hit wonder" effect where that one graduate is simply an outlier for that program. We cannot differentiate between these two possibilities. We also do not differentiate between single-authored and co-authored efforts, or attempt to control for the significance of a publication by accounting for the number of published pages.

An additional concern is the relatively rare event of publishing in a top field journal. Small numbers of publications interact with the associated problems of small number samples. This is more problematic for some fields than others, and in fact leads to some fields being dropped from discussion entirely. A very low number of graduates, or lack of specified top field journals altogether, requires us to leave some of the fields out of the analysis entirely (A - General Economics; B - Methodology and History of Economic Thought; M - Business Administration and Business Economics, and P - Economic Systems). Finally, additional factors, such as economic school of thought and institution of employment have an influence on any attempt to rank specialty journals. As a consequence, the results produced by the specialty publication analysis are somewhat inconclusive.

Summary statistics by field are presented in Table A. Some fields clearly have more graduates than others, from International Economics (F) with nearly 500 to Law and Economics (K) with just 29. There are clearly differences in publishing propensity of graduates across fields. Overall, nearly half (47\%) of all graduates in the sample published at least one article. In all fields except Law and Economics, no fewer than $40 \%$ of graduates published at least one paper in the Econ Lit journals. Overall fewer than on quarter of the graduates published even a single article in a top 36 journal, however that masks considerable variability across fields. Approximately $40 \%$ of the graduates in Mathematical and Quantitative Economics (C) and Economic History (N) published at least one article in the top 36 journals, while for graduates from several other fields (F, G, K, L, O, Q, R.) less than $20 \%$ do so.

The difference in publishing output across fields also shows in average publications per graduate. In every case, only 6 or 7 fields have publications per graduate higher than the overall average. Taking the average of the ranks in Table A, Mathematical and Quantitative (C) and Microeconomics (D) graduates were the most productive on average. Labor $(\mathrm{J})$ and Public $(\mathrm{H})$ graduates were also highly productive on average. Some fields, perhaps due to 
proportionally more non-academic employment opportunities, are ranked lower. While Development and Growth (O) graduates churned out 762 publications overall, this was over a large number of graduates with relatively few publications in top journals. Law and Economics (K) claims very few graduates or publications. Graduates in Agricultural Economics $(\mathrm{Q})$ put out a fair number of publications, but there were a large number of graduates and very few publications in the top 36 journals. Regional Economics (R) has a low number of relatively unproductive graduates. While we do not discuss several fields with the least-productive graduates, the summary tables for those fields are presented for the interested reader (Law and Economics (K), Industrial Organization (L), Agricultural and Natural Resource Economics (Q), and Regional Economics (R)).

\section{RESULTS}

\section{Aggregate Productivity in all Fields}

Table B1 ranks productivity of graduates in all fields in all journals by program. Table B2 is also an aggregated (over fields) ranking, but only counting publications in the top 36 journals. In general, many of the schools ranked highest in the previous literature are ranking very highly here - Harvard, Yale, Chicago and the like. However, due to the broader sample in this work and the fact our sample period is later in time differences do emerge. For example, comparing Table B2 to Table II in Collins, Cox and Stango (2000), UC San Diego ranks third in our data while only ranking 30 in Collins et al. Several programs rank higher in our study, some programs which are not in Collins' et al sample at all. Similarly, some programs rank rather lower here than in Collins et al. A comparison between Tables B1 and B2 show that the same programs tend to occupy the top ranks regardless of whether or not journal quality is controlled for. While the differences are of interest, in the interest of expediency we proceed to discuss the results for the individual fields.

In what follows, tables are designated first with the letter corresponding to the relevant field, and then with a number. The first such table ranks programs according to the average number of publications in all journals by graduates with dissertations specified by the degree-granting institution as being in that field. The second such table ranks programs according to the average number of publications in the top 36 journals by those same graduates, and the third such table ranks programs by the average number of publications in top field journals by those same graduates.

\section{C - Mathematical and Quantitative Methods}

\section{All Publications per Graduate}

One phenomenon that we see is that due to a certain amount of specialization, the average publications per graduate is higher for the top ranked programs (Table C1) than for the aggregated average (Table B1). The top four programs in Mathematical and Quantitative Methods (C) have at least 10 publications in all journals per graduate in that field, where the top four for the aggregate have closer to six publications per graduate. However, by the time we get to the bottom of the top 15 for the field, the divergence is substantially lessened with the average for (C) grads and the aggregate pool both within a fraction of four.

In general, certain fields are much more prominent in the larger programs that are the most effective at producing publishing grads, and which themselves tend to have the top faculty publishers. As a general rule, this tends to be the fields that are more theoretical or foundational as opposed to more applied. Mathematical and Quantitative Methods happens to be one of those fields. Of the 16 programs we note (Table C1), all but five (New School, SUNY Albany, Purdue, U. Alabama, and Johns Hopkins) are in the top 20 of our overall aggregated rankings. In addition those five tend to be small programs (with no more than three graduates in this field during the sample period).

This same degree of relative specialization means that some programs in the top of the aggregate rankings don't appear in the field rankings for field C. Within the top 15 on the aggregate list (Table B1), over half do not appear on the C field list including California Institute of Technology, U. Iowa, U. Chicago, Tulane, Yale, Clark, 
Arizona State, and Virginia Polytechnic. Notably, most of these programs also have a fairly low total number of graduates during the sample period suggesting that these schools may be specialized in other fields. Notably, this is about the only field in which U. Chicago does not show up in the top 15 at all. This result highlights the fact that sometimes highly regarded programs have many graduates producing in the field, but also have many non-productive graduates.

\section{Top 36 Publications per Graduate}

When we look at publications in the top 36 journals, we see that the specialization spread is a bit more pronounced (Table C2). The average number of publications in top journals at the top of the ranking in this field is double that of the aggregate average, and nearly double by the $15^{\text {th }}$ position though still substantially less than for the top positions. We also see this increased specialization in that fewer programs are on both lists; of the top 20 in the aggregate (Table B2), only 9 are in the top 15 for this field in the top journals as opposed to 11 for all publications. Princeton and Harvard claim the top spots, followed by Texas A\&M and then two UC programs, Berkeley and San Diego. As for the top 15 in our ranking in this field that are not in the top 20 of the aggregate ranking, just as for all journal publications they have low numbers of grads, but aside from the New School they are all different schools. Notably, $\mathrm{C}$ graduates overall have the highest average rate of publications in the top 36 journals (1.4767 per grad), and a rate more than double the average of all $\mathrm{PhD}$ recipients in our sample (0.664).

\section{Top Field Publications per Graduate}

$\mathrm{C}$ is one of the few fields in which we find a non-trivial number of publications in those identified as top field journals. The graduates from the top programs are producing 3 or more publications in top field journals over the period on average, whereas even by the $15^{\text {th }}$ rank that number has dropped to only one such article for every 3 graduates. As can be seen in Table $\mathrm{C} 3$, the top five in this list are all in the top ranks in most or all of the aggregate rankings and after these the average number of publications in top field journals has dropped off significantly. In this list, Indiana U, U. Wisconsin-Madison, USC and Duke all make their debut in the field while the New School can no longer claim a place as it did for the other journal groupings.

On the whole, relatively few programs make an appearance in all 3 lists for $\mathrm{C}$ graduates: Harvard, MIT, Princeton, Texas A\&M, UC-Berkeley, and UC-San Diego. We would hazard to say that our data suggests these to be the most successful programs at producing publishing graduates in this field.

\section{D - Microeconomics}

\section{All Publications per Graduate}

Doctoral graduates in the declared field of Microeconomics (D) are on average the most productive publishers, with an average of 4.615 publications per grad vs. 2.749 per grad over all fields. This may be attributed to their general interest in the larger field than a specific subcategory. Comparing the top 15 list of programs ranked by average publications per D graduate (Table D1), we find that the average productivity of those programs is significantly higher than programs of the same rank in the aggregate rankings of publications per graduate by program (Table B1). In this comparison, programs in the top ranks of Table D1 (Florida State, Tulane, U. Connecticut, Iowa State, and Yale) produce more than 10 publications per graduate even though this is over relatively few graduates. Even the number 15 program in Table D1 has a higher publication per D graduate average than the top program in Table A for all graduates. For all the publishing power of the grads of these programs, only 5 place in the aggregate top 20 (of Table A, being Tulane, Yale, Harvard, U. Virginia, MIT, and Michigan) and only 5 more place in the aggregate top 50. While Connecticut and Iowa State rank highly in this list, they (along with Pennsylvania State, Rutgers, Iowa, and Michigan) do not appear on any of the other lists for this field (Tables D2 or D3). 


\section{Top 36 Publications per Graduate}

Microeconomic graduates are substantially more productive in delivering top journal publications with 1.389 per graduate compared to .664 overall. This is second only to graduates in Mathematical and Quantitative Economics (Field C). Just as for All Publications, all of the top 15 programs for producing publishing D graduates (Table D2) have higher graduate productivity than programs of the same rank in the aggregate rankings (Table B2). This difference is notably higher, in fact. Florida State stands out with a single particularly productive graduate, followed by Yale, Tulane, MIT and U. Virginia. No programs on this list are not in the aggregate top 50 (Table B2), with a full 10 in the aggregate top 20. Three programs make their lone appearance in the field in this list: Virginia Polytechnic Institute and State U., Maryland, and Northwestern.

\section{Top Field Journal Publications per Graduate}

All the programs putting out the largest number of D graduates appear in this list (Table D3). Typical of this category, the absolute number of publications involved is rather low. Yale is at the top, followed by Hawaii with a lone publication in the category. Hawaii's appearance is a strong illustration of the power of one particular graduate. Chicago, Harvard, and MIT follow Hawaii. A large number of programs make their sole appearance in the field on this list, most of the bottom 8 and 9 overall: Hawaii, Pittsburgh, Stanford, UCLA, Minnesota, Cornell U., California Institute of Technology, Columbia, and Pennsylvania.

Looking over all three ranking lists in the field, a few programs stand out as placing in all three: Harvard, MIT, and Yale. These would seem to be the top programs in preparing graduates in the field. A fair number place in at least two of the field lists and seem worthy of mention: Boston U., Brown U., Florida State, Indiana, New York U., Princeton, Tulane, Chicago, and Virginia.

\section{E - Macroeconomics and Monetary Economics}

\section{All Publications per Graduate}

Graduates in Macroeconomics and Monetary Economics (E) publish about the same amount as the average. As is typical for most fields, the top five schools (Table E1: MIT, Chicago, UC-San Diego, Massachusetts, Virginia, Princeton, and Notre Dame) have more publications than same-ranked programs on the aggregate list (Table B1). Notre Dame and Massachusetts, along with Purdue and Ohio State, do not appear in the aggregate top 50. Notre Dame and Massachusetts appear in no other ranking for this field, and neither do SUNY-Stony Brook, Washington U., or Virginia Polytechnic. Of the 15 programs, fully eight appear in the aggregate top 20 rankings for all publications per grad.

\section{Top 36 Publications per Graduate}

These graduates tend to publish slightly more on average in top journals, though only the top 5 in this list do better than same-ranked schools in the aggregate list. Moreover, this list is clearly dominated by programs on the aggregate top 20 list. With the exceptions of Purdue and Minnesota, all the top 10 on this list are in the aggregate top 20. MIT, Chicago, Virginia, UC-San Diego, and Purdue take the top spots. Only three programs do not appear in the aggregate top 50 programs for top journal publications at all: Purdue, Ohio State, and Rice. Rice does not appear in any of the other E field rankings either for that matter.

\section{Top Field Journal Publications per Graduate}

Graduates in Macroeconomics and Monetary Economics tend to have more publications in top field journals that is the average for all fields ( 0.2149 for the field compared to 0.1766 overall). Topping the list are Chicago, Purdue, Northwestern, Johns Hopkins, and MIT. Brown, Wisconsin, North Carolina and Florida make appearances with one or two top field publications by their collective pool of grads. 
Harvard, MIT, Princeton, Chicago, Purdue, Ohio State, and UC-San Diego all appear in each of the three lists and would seem to be the top programs for training publishing graduates. Johns Hopkins, Northwestern, Stanford, UC-Davis, UCLA, Minnesota and Virginia all appear in at least two of the listings.

\section{F - International Economics}

\section{All Publications per Graduate}

By far, more doctoral graduates were produced in this field than any other -499 . The next highest field (QAgricultural and Natural Resource Economics) had 406 graduates. A reflection of this is that on average International Economics graduates publish fewer articles than all grads (2.48 to 2.748 overall). However, all programs in this list had higher publications per grad than same-ranked programs in the aggregate ranking. In effect, International Economics produced some highly productive individuals at, otherwise, lesser-ranked schools. At the top of this list is Wayne State, though it does not appear on any other of the rankings in this field. Carnegie Mellon, MIT, Princeton, UC-San Diego and Alabama follow Wayne State. Fordham produced a fair number of productive graduates, though appears on none of our other field lists. 7 of the programs on this list are also in the top 20 of the aggregate rankings (MIT, Princeton, UC-San Diego, Arizona State, Yale, Michigan and Texas A\&M), and all but two in the top 50.

\section{Top 36 Publications per Graduate}

Once again, the top 50 programs in the aggregate rankings dominate the field. Washington and Alabama stand out as lower ranked programs producing notable results. Harvard makes its only appearance in the field here. The top five in this list area all in the top 12 aggregate ranking: UC-San Diego, Carnegie Mellon, MIT, Princeton, and Arizona State. While these programs turned out grads that were more productive than same-ranked programs in the aggregate list, that is only the case for those. Of the 18 programs listed, 11 of them are in the aggregate top 20. Arizona State is particularly notable in this group in that even though it does not appear in the top field journal list, two thirds of all its graduate were in this field and it does rank in the top 10 of both the top journal ranking and all journal ranking in this field.

\section{Top Field Journal Publications per Graduate}

International Economics graduates, on average, published more in top field journals that all graduates. This may be a reflection of better specification of top field journals for this field. Princeton, Syracuse, U. Washington and MIT occupy the top slots in this list. Georgia, UCLA, Minnesota, and UC-Davis make their lone field appearances here.

Overall, eight programs appear in all three of these field lists and so could be considered the top programs in the field: Carnegie Mellon, MIT, Princeton, Syracuse, UC-San Diego, Michigan, Pennsylvania, and Yale. Arizona State, Columbia, Texas A\&M, Chicago, Rochester and U. Washington each appear on two of the lists. A further 11 programs appear but once - a lot, but not as many as in some other fields.

\section{G - Financial Economics}

\section{All Publications per Graduate}

Financial Economics appears to be a field where a few key graduates have a particularly large impact on the rankings. Connecticut, Purdue, Utah, Massachusetts, UC-Riverside and the New School for Social Research all appear in this list though they are not in the aggregate top 50 nor do they appear on any other Financial Economic's lists. Claremont Graduate School and Iowa appear on one of the other field lists, but are not in the aggregate top 50. As a result, over half the programs on this list are not in the aggregate top 50. Nonetheless, despite the fact that Financial Economics grads on the whole publish less than all grads (2.214 publications per G grad versus 2.749 publications per grad overall) all of the programs on this list trained grads that published at least as much as similarly 
ranked programs in the aggregate ranking. Only five programs ranking in the aggregate top 20 appear on this list: California Institute of Technology, MIT, Texas A\&M, Michigan and UC-San Diego.

\section{Top 36 Publications per Graduate}

As in many applied fields, students from schools such as Chicago and the California Institute of Technology to this list, along with Stanford, UCLA and Yale. However, beyond those first two Financial Economics grads aren't publishing as much as the average for all fields in the top journals, either on the whole or comparing like-ranked programs across this field list and the aggregate list. New York U., Rutgers and U. Wisconsin-Milwaukee appear in the field on this list, but this list only. This list has more representation by programs in the aggregate top 20 list and the aggregate top 50 list.

\section{Top Field Journal Publications per Graduate}

While many programs produce a graduate getting at least one publication in a top field journal, the large total number of graduates results in a low average for Financial Economics graduates (0.1444). The top ranked programs include Claremont Graduate School, MIT, Chicago, Stanford, Georgia and Duke. However, Harvard Grads produced the most pubs in top field journals with 11. Virginia, Iowa State, and Washington U. make their lone appearance in the field in this list by virtue of a single publication by a Financial Economics grad in a top field journal.

Only three programs make all three lists - Claremont Graduate School, Duke and MIT. A number make two appearances: Cal. Inst. Tech., Harvard, Pennsylvania State, Princeton, Stanford, UCLA, UC-San Diego, Iowa, Michigan and Yale. 15 programs make a lone appearance, a rather large number within the scope of this study.

\section{H - Public Economics}

\section{All Publications per Graduate}

Public Economics has a rather large, but consistent, group of programs that consistently show up in our rank listings for the field. The pre-dominance of this group in the field is partly evident in the fact that graduates of many programs are more productive than similarly ranked programs in the aggregate list. However, on average, Public Economics graduates publish slightly less than is the average for all graduates (2.61 in $\mathrm{H}$, versus 2.749 overall). SUNY-Buffalo tops this list with a particularly productive graduate, but appears on none of the other field lists. Chicago and Purdue also appear on this list only. Only four programs on this list also appear in the aggregate top 20 list for all publications per grad - Rochester, Princeton, Chicago and MIT. Six programs on this list are not even in the aggregate top 50. This is a rather large number in this study (U. Connecticut, UC-Santa Barbara, Georgia State, Florida State, Purdue and Boston U appear on this list, but on the aggregate top 50.).

\section{Top 36 Publications per Graduate}

Unlike the "all publications" field list, Public Economics graduates publish slightly more per graduate than the sample population (0.831 to 0.664$)$. We also see many more programs on this list also on the aggregate top 20 list for top journal publications per graduate - nine, in fact. Only Rice University appears on this list but no other in the field. It is also, along with Illinois and Connecticut, only one of three programs not in the aggregate top 50.

Boston U., Georgia State, MIT, Northwestern, Princeton, UCLA, Illinois and Rochester all appear on each of the three lists for the field and would seem to be the top programs for producing publishing graduates. Indiana, Michigan State, Texas A\&M, Tulane, UC-Santa Barbara, Connecticut and Virginia all appear on at least 2 of the field lists, with only 5 programs only appearing on one of the three lists in the field. Again, this is indicative of the predominance of a somewhat broad set of programs with a certain dominance in the field. 


\section{I - Health, Education and Welfare}

\section{All Publications per Graduate}

Graduates in this field tend to be among the more productive publishers. Every program in this ranking produces graduates that are on average more productive than the similarly ranked program in the aggregate rankings. Harvard, MIT, U. Washington, Minnesota and Wyoming take the top spots, with their graduates on average producing at least 8 publications over the sample period. All but three programs (U. Washington, West Virginia, and North Carolina State) are in the aggregate top 50, though only six are in the aggregate top 20. U. Washington, NC State and Minnesota do not appear in either of the other field lists. Of the programs in this list, Wisconsin by far produced the most graduates in the field, followed by MIT and Harvard.

\section{Top 36 Publications per Graduate}

Health, Education and Welfare graduates on average publish nearly twice as many articles in top journals as the average for all graduates. They publish 1.116 articles for the field versus 0.664 overall. Harvard, MIT and U. Wyoming occupy the first, second and fifth ranks respectively, with SUNY-Stony Brook and West Virginia U. taking the third and fourth ranks. For the top eight ranks in this list, the graduates of those programs are more productive than graduates of a comparably ranked program in the aggregate rankings, with the rest of the programs in this list not far below. Only American U. and Temple, at the bottom of this ranking, are not in the aggregate top 50.

\section{Top Field Journal Publications per Graduate}

Only six programs had graduates that published anything in the top journals of the field, and the overall average publishing rate was a bit lower than for all fields. Five of these programs appear in ever field list and so would seem to be the most successful at preparing graduates in the field to publish: SUNY-Stony Brook, Harvard, Wyoming, MIT, and Stanford.

The sixth program in U. Wisconsin, which along with Louisiana State, Princeton, Chicago, Michigan, Pennsylvania, and West Virginia appear in at least two of the lists for this field.

\section{J - Labor and Demographic Economics}

\section{All Publications per Graduate}

Labor and Demographic Economics graduates are fairly active publishers on the whole. This extends to many of the aggregate top 50 programs. Labor and Demographic Economics graduates on the whole produced 3.11 publications per graduate, against 2.749 for all graduate. The top 15 programs in the field had higher levels of publications per graduate than the comparably ranked programs in the aggregate for all 15 ranks with the top 5 (Clark U., Wayne State, Princeton, South Carolina and Duke) all over 9 publications per grad. Clark and South Carolina, along with UC-Berkeley, U. Wisconsin-Milwaukee, American U. and New York U. make their only appearance in the field in this ranking.

\section{Top 36 Publications per Graduate}

On average Labor and Demographic Economics graduates publish more often than average in top journals, 0.745 per graduate as opposed to an overall average of 0.664 . The top ranking programs tend to turn out graduates more productive than those same ranks in the aggregate (Princeton, Chicago, Yale, Boston U., and Duke), and several are top-ranked schools in their own right. The top 9 in this ranking are all in the top 50 in the aggregate rankings. In fact, only SUNY-Binghamton, Ohio State, and Iowa State are not in the aggregate top 50. 


\section{Top Field Publications per Graduate}

This Field presents a full list of 15 top producers in top field journals. A number of programs make their lone field appearance here: UC-Santa Barbara, Georgetown, Illinois, Wisconsin, Kentucky and Harvard. Princeton, Iowa State, Chicago and Virginia claim the top spots. A large number of programs make several appearances in these field rankings. Boston U., Princeton, SUNY-Binghamton, Chicago, and Yale each appear in every listing. Duke, Iowa State, MIT, Syracuse, Michigan, Pittsburgh, Virginia, and Wayne State all make two showings.

\section{N - Economic History}

\section{All Publications per Graduate}

Economic History appears to be a field where many established names appear prominently. The top 15 include a high number of programs that rank in the top 15 in the aggregate rankings, over half, and all but three others (Boston U., Ohio State, and Washington State) showing in the top 50 aggregate rankings. The average publications per grad in the field is high. Most programs rank higher than the comparable rank in the aggregate rankings. Four schools appear in this ranking, but none other for the field including Boston U., U. Rochester, U. Pittsburgh and U. Michigan. Topping the list are California Institute of Technology, Clark U., and Boston U. producing a single very productive graduate each, and U. Chicago with a few more. In general, programs produce relatively few, but compared to the aggregate rather productive graduates in the field at the top ranks, with an overall average 3.88 publications per graduate in the field versus 2.75 for all graduates.

\section{Top 36 Publications per Graduate}

While the graduates of the top four ranked programs for the field see greater productivity than the aggregate rankings. However, average productivity falls off quickly. Seven of the schools in the field ranking are also in the top 20 of the aggregate ranking, with another four in the top 50. Northwestern, UC-Davis, MIT and Stanford make their lone appearance for the field in this ranking. Topping the list are U. Chicago, Rutgers, Cal. Institute of Technology and Harvard. Again, graduates in this field tend to be rather productive at publishing in top journals, with 1.246 publications per Economic History graduate versus 0.664 on average over all graduates.

A number of programs make it into these two lists, but none of their graduates published anything in a top field journal. Clark U., Ohio State, Rutgers, U. Illinois, Washington State and U. Washington are all notable in that regard.

\section{Top Field Journal Publications per Graduate}

Only five programs produced graduates publishing in the top field journals. These five programs appear in every ranking for the field: U. Chicago, Cal. Institute of Tech., UC-Berkeley, UCLA, and Harvard. However, like in many other fields the amount of publishing by $\mathrm{N}$ grads in top-ranked journals in the field is rather low.

\section{O - Economic Development, Technological Change and Growth}

\section{All Publications per Graduate}

There are two notable results in field of Economic Development, Technological Change and Growth. First, fairly few of the top 20 schools in the aggregate rankings appear in the top 15 for this field. Second, while the publications per graduate are higher than the aggregate average for the top few school, by the time we get down to rank 15 the average is lower than for the aggregate. This is true for both all publications per Economic Development graduate and for top journal publications per graduate. This reflects that some programs are producing highly productive students, but on average Economic Development graduates are generally less productive than in the aggregate across all fields. It is likely that this is a field-producing graduates who actually go on to applied work. As a result, they do not show as much academic productivity. 
Reviewing all publications specifically, it is clear that the top seven programs possess graduate productivity in excess of the aggregate average. U. Houston, Princeton and Yale are all in the aggregate top 20 among these, but the rest are not. Penn State and U. Pittsburgh are in the aggregate top 50, but SUNY Albany and NC State are not. All of these programs have few grads in Economic Development. The bottom half of the list has average publications per Economic Development graduate slightly less than for the aggregate. Chicago, UC-Berkeley and Harvard are top schools that appear here though Berkeley doesn't appear in any of the other rankings for this field. Neither do American U., UC-Riverside or UC-Davis though they do appear in this one. U. Texas and American U. are also notable as programs not appearing in the aggregate top 50 which appear in this list.

\section{Top 36 Publications per Graduate}

The average top journal publications per graduate are significantly higher than for the aggregate for the top few programs, but that average drops off very quickly for Economic Development graduate where by the $6^{\text {th }}$ rank already graduates in this field are less productive in top journal publications than the average for the aggregate. However, very few of the top 15 are in the top 20 in the aggregate, though very few are not in the aggregate top 50. Princeton, U. Chicago, Yale and Harvard are those few at the tops in both. SUNY-Albany, NC State, U. Georgia, Michigan State, and U. Texas are those programs not in the aggregate top 50, and all but Michigan State have no more than two Economic Development grads in the sample period. A number of schools make their sole appearance in the Economic Development list in the top journal subset: Brown, U. Georgia, Michigan State, U. Pennsylvania, U. Wisconsin and U Iowa However, it should be noted that even by the last five ranks the only about every other graduate is publishing a single article in a top journal on average, and in some cases one grad is carrying that whole load. Notably, as for all the Economic Development all journal ranking, Houston, Penn State, and Princeton share the top three ranks.

\section{Field Publications per Graduate}

Only ten programs produced a graduate who published anything at all in a top field journal. The majority of these are programs showing up in the field all journal and top journal rankings described above. The other three don't show up in either of the other rankings, those programs being Fordham, UCLA, and Columbia. Regardless, the actual averages per grad are quite low, the median in the top 15 being between 0.273 and 0.25 , and in general this field sees one of the lowest rates of grads publishing in top field journals with an overall average of 0.04 compared to an average of 0.17 for all fields.

A fair handful of schools shows in all three $\mathrm{O}$ rankings that we would again consider the top programs in the field: Princeton, Penn State, Harvard, SUNY-Albany, U. Chicago, U. Houston, and Yale.

\section{CONCLUSION}

This paper extends the research on publishing productivity, ranking programs not by the productivity of their faculty but of their graduates, and utilizing a broader sample of both programs and publications than heretofore attempted. We further expand this line of inquiry in what is the primary contribution of this paper by examining publishing patterns by field. If the graduate publication metric is more relevant for prospective graduate candidates or programs interviewing new faculty, this issue continues to be relevant and at times more aptly targeted within the area of field.

Prospective students, as well as colleges hiring new faculty, often conduct their search based on fields of specialization. A university seeking a labor economist would be interested in which program produced labor economists with a history of publishing. If publishing is a necessary component of the position, students interested in pursuing a career in academics with a specialty in financial economics, may wish to attend a program that has a track record of graduating financial economists who publish. This paper finds that some schools do specialize in producing active academic economists in specific fields despite their less stellar performance overall. Within Labor (JEL code J), for example, both SUNY-Buffalo and Boston University place in the rankings here, but are not noted for overall graduate productivity. A number of other programs make decent showings. As well, some highly reputable and 
effective programs produce highly productive graduates in many fields, but not all. While Princeton, Chicago and Yale rank highly in Labor, Harvard appears in the Labor ranking once only just barely.

An additional contribution of the article is that it provides more insight into the publishing patterns of the graduates of a large number of programs (120) and the publishing patterns of the specialties within these schools. Once again, we find that there are notable differences in the publishing patterns between fields. In effect, some fields, perhaps due to a non-academic employment effect, produce fewer pieces of academic literature than others. This issue is important to consider in hiring and promotions since it argues against uniform standards. We tend to clearly see more publishing out of the more "academic" fields, such as Mathematical and Quantitiative (C), Microeconomics (D) or Economic History (N). Agricultural Economics (Q), on the other hand, finds ready application in extension offices throughout the United States and government positions in many other countries, occupations where publishing in academic journals is a very low priority. Economic Development $(\mathrm{O})$ often attracts students from outside the United States who expect to return to government positions in their own countries, again with little expectation of academic publishing.

Finally, the pre-eminent programs continue to stand out due to output quality and quantity. By a variety of measures they tend to rise to the top. This is consistent with earlier studies. However, there are opportunities for programs motivated to excel to create niche programs by nurturing graduates in specific fields. In addition, our research may be useful to departments searching for candidates who are most likely to publish.

\section{References}

1. Axarloglou, Kostas, and Vasilis Theoharakis. "Diversity in Economics: An Analysis of Journal Quality Perceptions". mimeo, 2003

2. Collins, Jeffery T., Richard Guy Cox, and Victor Stango. "The Publishing Patterns of Recent Economics Ph.D. Recipients". Economic Inquiry, Spring 2000, 358-367.

3. Gilley, Otis W. "A Ranking of the Top U.S. Economics Departments by Research Productivity of Graduates: A Comment". Journal of Economic Education, Fall 1986, 307-309.

4. Graves, Philip E., James R. Marchand, and Randall Thompson. "Economic Department Rankings, Research Incentives, Constraints and Efficiency." American Economic Review, December 1982, 1131-1141.

5. Hirsch, et al. "Economic Departmental Rankings: Comment". American Economics Review, September 1984, 827-833.

6. Hodgson, Geoffrey M. and Harry Rothman. "The Editors and Authors of Economics Journal: A Case of Institutional Oligopoly.” Economic Journal, February 1999, 165-186.

7. Hutchinson, E. Bruce and Terry L. Zivney. "The Publication Profile of Economists." Journal of Economic Education, Winter 1995, Pp. 59-79.

8. Kalaitzidakis, Pantelis, Theofanix P. Mamuneas, and Thanasis Stengos. "Rankings of Academic Journals and Institutions in Economics." Journal of the European Economic Association, December 2003, 13461366.

9. Laband, David N. "A Ranking of the Top U.S. Economics Departments by Research Productivity of Graduates." Journal of Economic Education, Winter 1986a, 70-76.

10. Laband, David N. "A Ranking of the Top U.S. Economics Departments by Research Productivity of Graduates: Reply." Journal of Economic Education, Winter 1986b, 311-314.

11. Moore, William J. "The Relative Quality of Economics Journals: A Suggested Rating System". Western Economics Journal, June 1972, 156-159.

12. Neimi, Albert W. "Journal Publication Performance During 1970-1974: The Relative Output of Southern Economics Department". Southern Economic Journal, July1975, 97-106.

13. Scott, Loren C. and Peter M. Mitias. "Trends in Rankings of Economics Department in the U.S.: An Update." Economic Inquiry, Vol 34 1996, 378-400.

14. Trembay, Carol H., Victor J Tremblay, and Blunglak Lee. "Filed Publishing Performance of U.S. Economics Departments." Atlantic Economic Journal, June 1990, 37-48.

15. Tschirhart, John. "Ranking Economic Departments in area of Expertise." Journal of Economic Education, Spring 1989, 199-222. 
Appendix 1 - Top Field Journals

C Mathematical and Quantitative Methods: Econometrica, J. Econometrics, J. Finance

D Microeconomics: Econometrica; J. Finance; Rev. of Economic Studies

E Macroeconomics and Monetary Economics: J. Monetary Econ.; J. Money, Credit and Banking: J. Political Economy

F International Economics: J. Intl. Econ.; Intl. Econ. Review; European Econ. Rev.

G Financial Economics: J. Finance; J. Financial Econ.; Rev. Economics and Statistics

H Public Economics: J. Public Economics; Amer. Econ. Rev.; J. Political Economy

I Health, Education and Welfare: J. Labor Econ.; J. Public Econ.; Rev. Econ. and Statistics

J Labor and Demographic Economics: J. Labor Economics; Quarterly J. of Economics; Southern Econ J.

L Industrial Organization: RAND J. of Economics; J. Law and Economics; Amer. Econ. Review

$\mathrm{N}$ Economics History: Quarterly Journal of Economics; J. of Monetary Economics

O Economic Development, Technological Change and Growth: J. Econ. Development; Intl. Econ. Rev.; Economic Journal

Q Agricultural and Natural Resource Economics: J. Public Econ.; Intl. Economic Rev.; J. Econ. Theory

R Urban, Rural and Regional Economics: Southern Econ. J., Amer. Econ. Rev.; J. Labor Econ.

Appendix 2 - Top 36 Journals (Collins, Cox, and Stango, 2000)

American Economic Review, Econometrica, Economic Inquiry, Economic Journal, Economica, Industrial and Labor Relations Review, International Economic Review, Journal of Business, Journal of Business and Economic Statistics, Journal of Development Economics, Journal of Econometrics, Journal of Economic Dynamics and Control, Journal of Economic History, Journal of Economic Theory, Journal of Finance, Journal of Financial Economics, Journal of Labor Economics, Journal of Human Resources, Journal of International Economics, Journal of International Money and Finance, Journal of Law and Economics, Journal of Law, Economics and Organizations, Journal of Legal Studies, Journal of Monetary Economics, Journal of Money, Credit and Banking, Journal of Political Economy, Journal of Public Economics, Journal of Regional Science, Journal of Urban Economics, National Tax Journal, Public Choice, Quarterly Journal of Economics, RAND, Review of Economic Studies, Review of Economics and Statistics, Southern Economic Journal 


\begin{tabular}{|c|c|c|c|}
\hline University & \#Grads & nubs/arad & Rank \\
\hline Princeton University & 56 & 6.84 & 1 \\
\hline Massachusetts Institute of Tech & 111 & 6.47 & 2 \\
\hline U. California, San Diego & 21 & 6.14 & 3 \\
\hline California Inst of Technology & 12 & 5.25 & 4 \\
\hline University of Iowa & 17 & 5.06 & 5 \\
\hline University of Chicago & 107 & 5.05 & 6 \\
\hline Tulane University & 6 & 5.00 & 7 \\
\hline University of Rochester & 37 & 4.95 & 8 \\
\hline Yale University & 68 & 4.85 & 9 \\
\hline Harvard University & 178 & 4.83 & 10 \\
\hline University of Houston & 20 & 4.50 & 11 \\
\hline Clark University & 10 & 4.40 & 12 \\
\hline Arizona State University & 9 & 4.22 & 13 \\
\hline Texas A\&M University & 33 & 4.03 & 14 \\
\hline Virginia Polytech Inst \& State U & 13 & 3.92 & 15 \\
\hline University of Michigan & 71 & 3.73 & 16 \\
\hline Stanford University & 119 & 3.73 & 17 \\
\hline Washington University & 33 & 3.64 & 18 \\
\hline University of Virginia & 30 & 3.57 & 19 \\
\hline U. California, Berkeley & 120 & 3.43 & 20 \\
\hline Duke University & 41 & 3.29 & 21 \\
\hline Wayne State University & 16 & 3.25 & 22 \\
\hline Louisiana State University & 5 & 3.20 & 23 \\
\hline U. California, Riverside & 6 & 3.17 & 24 \\
\hline University of Wyoming & 6 & 3.17 & 24 \\
\hline U. California, Los Angeles & 86 & 3.03 & 26 \\
\hline Northwestern University & 40 & 3.00 & 27 \\
\hline Syracuse University & 18 & 3.00 & 27 \\
\hline Indiana University & 41 & 2.85 & 29 \\
\hline Pennsylvania State University & 31 & 2.84 & 30 \\
\hline Southern Methodist University & 8 & 2.75 & 31 \\
\hline Iowa State University & 54 & 2.74 & 32 \\
\hline Michigan State University & 48 & 2.69 & 33 \\
\hline University of Minnesota & 99 & 2.69 & 34 \\
\hline University of Florida & 23 & 2.61 & 35 \\
\hline SUNY, Stony Brook & 30 & 2.57 & 36 \\
\hline University of Pennsylvania & 87 & 2.53 & 37 \\
\hline University of Pittsburgh & 38 & 2.45 & 38 \\
\hline Rutgers University & 27 & 2.41 & 39 \\
\hline Fordham University & 23 & 2.39 & 40 \\
\hline New York University & 44 & 2.32 & 41 \\
\hline University of Wisconsin & 113 & 2.31 & 42 \\
\hline University of California, Davis & 27 & 2.30 & 43 \\
\hline University of North Carolina & 17 & 2.29 & 44 \\
\hline University of Illinois & 106 & 2.26 & 45 \\
\hline SUNY, Buffalo & 28 & 2.25 & 46 \\
\hline Johns Hopkins University & 38 & 2.24 & 47 \\
\hline University of Georgia & 22 & 2.18 & 48 \\
\hline Columbia University & 67 & 2.18 & 49 \\
\hline Carnegie Mellon University & 7 & 2.14 & 50 \\
\hline
\end{tabular}

Table B2 - Top 36 Journal Publications per Graduate \begin{tabular}{|l|l|l|l|}
\hline University & \#Grads & pubs/grad & Rank \\
\hline
\end{tabular} \begin{tabular}{|l|c|c|c|}
\hline Massachusetts Institute of Tech & 111 & 2.71 & 1
\end{tabular} Princeton University U. California, San Diego University of Chicago California Inst of Technology Harvard University University of Rochester Yale University Arizona State University University of Virginia Virginia Polytech Inst \& State U Carnegie Mellon University Texas A\&M University Tulane University Stanford University Northwestern University U. California, Los Angeles Syracuse University Louisiana State University Indiana University

University of Michigan

University of Houston

University of Pennsylvania

Columbia University University of Pittsburgh Florida State University Rutgers University Pennsylvania State University New York University Washington University SUNY, Stony Brook West Virginia University Brown University U. California, Berkeley University of Wyoming University of Kentucky University of Arizona University of Minnesota Johns Hopkins University Georgia State University U. California, Santa Barbara University of Wisconsin Duke University University of Iowa University of California, Davis Wayne State University Cornell University University of Maryland Michigan State University Boston University

\begin{tabular}{|c|c|c|}
\hline 111 & 2.71 & 1 \\
\hline 56 & 2.63 & 2 \\
\hline 21 & 2.00 & 3 \\
\hline 107 & 1.94 & 4 \\
\hline 12 & 1.67 & 5 \\
\hline 178 & 1.60 & 6 \\
\hline 37 & 1.49 & 7 \\
\hline 68 & 1.47 & 8 \\
\hline 9 & 1.33 & 9 \\
\hline 30 & 1.33 & 9 \\
\hline 13 & 1.23 & 11 \\
\hline 7 & 1.14 & 12 \\
\hline 33 & 1.06 & 13 \\
\hline 6 & 1.00 & 14 \\
\hline 119 & 0.92 & 15 \\
\hline 40 & 0.85 & 16 \\
\hline 86 & 0.85 & 17 \\
\hline 18 & 0.83 & 18 \\
\hline 5 & 0.80 & 19 \\
\hline 41 & 0.78 & 20 \\
\hline 71 & 0.77 & 21 \\
\hline 20 & 0.70 & 22 \\
\hline 87 & 0.69 & 23 \\
\hline 67 & 0.61 & 24 \\
\hline 38 & 0.61 & 25 \\
\hline 25 & 0.60 & 26 \\
\hline 27 & 0.59 & 27 \\
\hline 31 & 0.58 & 28 \\
\hline 44 & 0.57 & 29 \\
\hline 33 & 0.55 & 30 \\
\hline 30 & 0.53 & 31 \\
\hline 17 & 0.53 & 32 \\
\hline 25 & 0.52 & 33 \\
\hline 120 & 0.51 & 34 \\
\hline 6 & 0.50 & 35 \\
\hline 18 & 0.50 & 35 \\
\hline 8 & 0.50 & 35 \\
\hline 99 & 0.49 & 38 \\
\hline 38 & 0.47 & 39 \\
\hline 11 & 0.45 & 40 \\
\hline 31 & 0.45 & 41 \\
\hline 113 & 0.44 & 42 \\
\hline 41 & 0.41 & 43 \\
\hline 17 & 0.41 & 44 \\
\hline 27 & 0.41 & 45 \\
\hline 16 & 0.38 & 46 \\
\hline 79 & 0.35 & 47 \\
\hline 60 & 0.35 & 48 \\
\hline 48 & 0.33 & 49 \\
\hline 52 & 0.33 & 50 \\
\hline
\end{tabular}


